\title{
Effect of multimode ultrasound assisted extraction on the yield of crude polysaccharides from Lycium Barbarum (Goji)
}

\author{
Rahma MUATASIM ${ }^{1}$, Haile MA ${ }^{1 \star}$, Xue YANG ${ }^{1}$
}

\begin{abstract}
The goals of this exploration were to find out the optimum conditions of ultrasound assisted extraction (UAE) of L. Barbarum crude polysaccharides. Furthermore, to research the impacts of three multi-frequency ultrasound assisted extraction modes on the yield of $L$. Barbarum crude polysaccharides. The results showed that by applying the traditional single-frequency UAE mode, the optimum extraction time was $30 \mathrm{~min}$, extraction temperature of $60^{\circ} \mathrm{C}$, and solid/liquid ratio of $20 \mathrm{~g} / 600 \mathrm{~mL}$, at a power density of $300 \mathrm{~W} / \mathrm{L}$, and ultrasound frequency of $28 \mathrm{kHz}$. Secondly; a comparison was carried out between three UAE modes using the optimum extraction conditions obtained previously. The energy aggregation counter flow dual-frequency UAE mode gave the highest yield of $38.93 \%$ of crude polysaccharides. Followed by the Opposite-sit dual-frequency UAE mode and the energy aggregation counter flow single-frequency UAE mode with yields of $33.60 \%$, and $26.38 \%$ of crude polysaccharides, respectively. As a result the ultrasound assisted extraction with dual-frequency mode is more effective for the extraction of L. Barbarum crude polysaccharides. Furthermore, the yield of crude polysaccharides increased by $73.41 \%$ using the dual-frequency ultrasound extraction compared to traditional hot water extraction.
\end{abstract}

Keywords: extraction; Lycium Barbarum; crude polysaccharides; ultrasound.

Practical Application: The extraction of Lycium Barbarum crude polysaccharides was examined utilizing ultrasound assisted extraction technique. The optimum extraction conditions were studied and applied on three extraction modes to discover the best extraction procedure.

\section{Introduction}

Lycium (Boxthorn) is a class of the nightshade family (Solanaceae), containing around 80 types of plants local all through the temperate and subtropical areas of the world (Xin et al., 2013). Lycium Barbarum, commonly named Wolfberry, Goji (Gouqi) in Chinese, is mostly found in dry, semi-saline environments. An extensive variety of Lycium Barbarum products have been produced in types of cosmetic products, dietary supplements, tea (Amagase, 2014), milk, juice, seed oil, and so on (Potterat, 2010). For more than 4000 years Lycium Barbarum has been consumed as nourishment and in traditional prescription (Amagase \& Farnsworth, 2011). Furthermore, the agriculture of Lycium Barbarum has been recorded for over 600 years in the Northwestern region of China, particularly Ningxia province which is additionally the authentic district of Chinese medication Lycii Fructus (Li, 2007; Potterat, 2010). Within the chemical composition of Lycium Barbarum, water-soluble glycoconjugates, (Lycium Barbarum polysaccharides or LBP) are the most researched components, which are evaluated to involve 5-8\% of the dried Goji (Amagase \& Farnsworth, 2011; Potterat, 2010).

Developing number of investigations of L. Barbarum, have led different clinical and fundamental examinations to look at the traditional impacts of the fruits given as a juice that is standardized for L. Barbarum polysaccharides (LBP)
(Amagase \& Farnsworth, 2011). Supporting the conventional uses and properties, recent investigations show that concentrates from L. Barbarum fruit, and its dynamic compounds, polysaccharides (LBP) have a scope of natural biological activities, counting impacts on neuro-protection, aging, diminish cholesterol level (Li, 2007), expanded digestion, glucose control in diabetics (Li, 2007; Potterat, 2010) glaucoma, anti-oxidant properties, improved immune responses (Bo et al., 2016), anti-tumor activity and cyto-protection (Amagase, 2014; Cui et al., 2012). Lycium Barbarum can be utilized as pharmaceutical for treatment and also as an ingredient in Chinese cooking (Xie et al., 2016).

Ultrasound has been utilized as a part of several food industry procedures, for example freezing, dehydrating (Fernandes et al., 2015), tempering, extraction, and cleansing (Chemat et al., 2011) due to its reduction in temperature, energy consumption, and production steps (Chemat et al., 2011). lately, ultrasound innovation has been observed to be a potential sustenance in food processing techniques (Ashokkumar, 2015). Ultrasound assisted extraction (UAE) is applied to recovering bioactive materials such as peptides (Kadam et al., 2015), polysaccharides (Cheung et al., 2013), polyphenolics, aromatic compounds, caffeine, theobromine (Peralta-Jiménez \& Cañizares-Macías, 2013), and functional compounds from herbal and animal sources (Vilkhu et al., 2008). Ultrasound waves after interaction with subjected plant 
material modify its physical and synthetic properties and their cavitation impact enhances the extraction yield and upgrades the mass transport by disrupting the plant cell walls (Cravotto \& Binello, 2016). UAE is a perfect strategy that limits the usage of considerable amount of solvents close by decreasing the working time (Chemat et al., 2011). Ultrasound can be easily examined on a laboratory scale, giving data suitable for large industrial scale (Cravotto \& Binello, 2016). Diverse ultrasound modes have been utilized for the recovery of high value components from numerous raw materials. For instance multi-frequency sonication mode turned out to be more successful to enhance hydrolysis and transformation rate of corn gluten meal (Jin et al., 2015). Ultrasound multi-frequency mode notably affects the extraction and activity of natural products (Yang et al., 2017). Ideal conditions can differ as indicated by the substance of intrigue and crude materials (Azmir et al., 2013; Cravotto \& Binello, 2016).

In this model, the optimization of polysaccharides extraction was carried out to find the optimum conditions using a single frequency ultrasound extractor. Later, these optimum conditions were applied on three ultrasound modes with different frequencies. The first mode was the energy aggregation counter flow single-frequency ultrasound extractor. The second mode was the energy aggregation counter flow dual-frequency ultrasound extractor. And the third mode was the opposite-sit dual-frequency ultrasound extractor (Figure 1a, b and c).

\section{Materials and methods}

\subsection{Materials}

The Lycium Barbarum (Goji) samples were provided by our school and purchased from Ningxia province. Dried Lycium Barbarum fruits were grounded by an electrical multi-function grinding machine (model LD-T400A, Meetingpoint trading company, China), into powder and sieved with a manual sieve size $(0.4) \mathrm{mm}$ and stored for farther use.

\subsection{Methods}

\section{Single frequency UAE optimization of crude polysaccharides}

As the first step of this study, the optimal conditions for the ultrasound assisted extraction (Time, Temperature, Solid/Liquid ratio) were investigated using an energy aggregation counter flow single-frequency ultrasound extractor Figure 1a. The fixed parameters were ultrasound power density of $300 \mathrm{~W} / \mathrm{L}, \mathrm{On} / \mathrm{Off}$ ultrasound time $5 \mathrm{sec} / 2 \mathrm{sec}$, and at a chosen frequency $28 \mathrm{kHz}$.
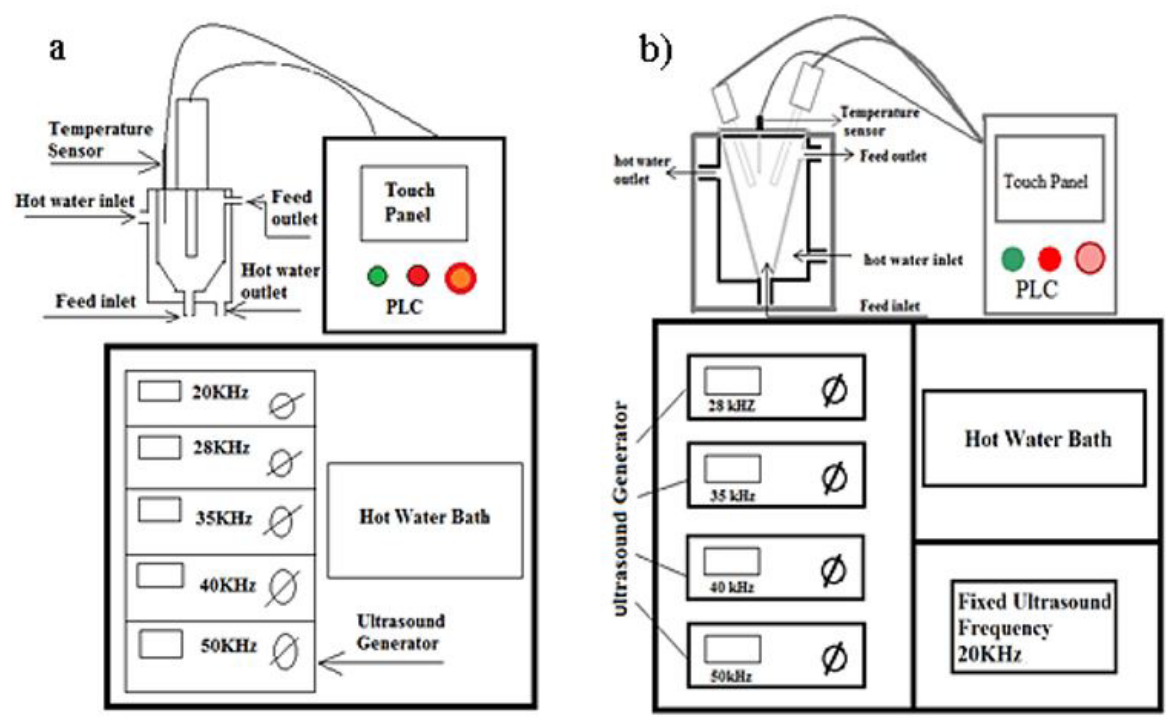

c

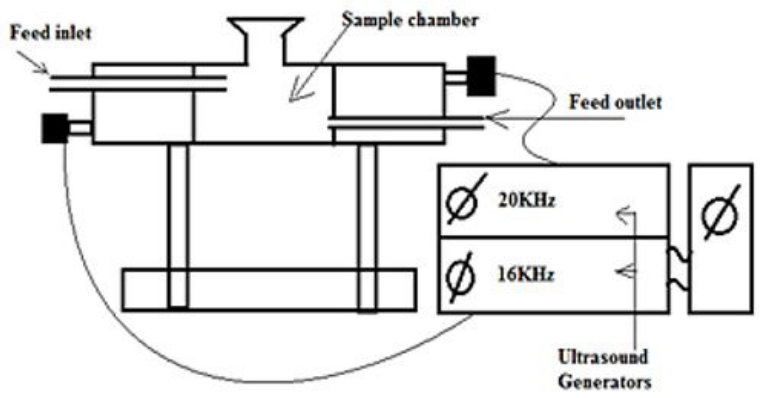

Figure 1. a) The energy aggregation counter flow single-frequency ultrasound extractor, b) The energy aggregation counter flow dual-frequency ultrasound extractor, and c) The opposite-sit dual-frequency ultrasound extractor. 
The first condition to be tested was the time, ranged $20,30,40,50$ and 60 mins at a temperature of $50{ }^{\circ} \mathrm{C}$ and solid/liquid ratio of $15 \mathrm{~g} / 600 \mathrm{~mL}$. The optimum extraction time obtained was applied to find out the perfect extraction temperature between $30,40,50,60$ and $70^{\circ} \mathrm{C}$ with a solid/liquid ratio of $15 \mathrm{~g} / 600 \mathrm{~mL}$. Two thermostat-controlled water baths were used to maintain the desired temperature controlled and constant. The circulation of the heated water and the sample in and out of the extractor was done by two circulation pumps -one for the sample and another for the temperature control- to maintain the temperature controlled.

And for the last condition, solid/liquid ratio of 5, 10, 15, 20 and $25 \mathrm{~g}$ - at a fixed volume of distilled water $600 \mathrm{ml}$ - was investigated using the optimum time and temperature obtained above. These tests were triplicated to reduce error.

\section{Hot water extraction}

Hot water extraction process was conducted as a control experiment. The extraction temperature was $90^{\circ} \mathrm{C}$ for $60 \mathrm{mins}$ and solid/liquid ratio was $20 \mathrm{~g} / 600 \mathrm{~mL}$ using a magnetic stirring hot water bath apparatus (DF-101S, Xiang Tian Experimental Instrument Factory, Changzhou, china) at a speed of $100 \mathrm{rpm}$.

\section{Extraction of crude polysaccharide}

After UAE, samples were centrifuged at $4000 \mathrm{rpm}$ for 15 mins each. The volume of the collected supernatant was then reduced to one-fifth using a rotary evaporator at $60^{\circ} \mathrm{C}$ under vacuum. The remaining solution was mixed with four times the volume of Ethanol (ethanol final concentration, 100\%) (Wu et al., 2007) and kept overnight at $4{ }^{\circ} \mathrm{C}$ (DuBois et al., 1956). Later the sample was centrifuged and freeze dried for 48 hours. The crude polysaccharides were weighed and the percentage yield of the crude Lycium Barbarum polysaccharide (L.B.P\%), were determined from the Equation 1 as follows (Raza et al., 2017; Wang et al., 2009).

$$
\text { L.B.P } \%=\frac{W}{W o} \times 100
$$

$\mathbf{W}(\mathrm{g})$ is the L.B.P dry weight, $\mathbf{W}_{\mathbf{o}}(\mathrm{g})$ is the raw material dry weight.

The conditions resolving the highest percentage yield of crude polysaccharide were based on the optimum conditions for a single frequency ultrasound extractor.

\section{UAE modes comparison}

The second part of the study was to apply the optimum conditions on the three UAE modes to compare the extracted crude polysaccharide. First mode was the energy aggregation counter flow single-frequency ultrasound extractor Figure 1a, consisting frequencies of 20,28, 35, 40 and $50 \mathrm{kHz}$. Secondly, energy aggregation counter flow dual-frequency ultrasound extractor Figure $1 \mathrm{~b}$ with $(20 / 28),(20 / 35),(20 / 40)$ and $(20 / 50)$ $\mathrm{kHz}$. And the third mode was the opposite-sit dual-frequency ultrasound extractor Figure 1c, having only three frequencies options $(20,16$, and $(20 / 16) \mathrm{kHz})$.

\section{Results and discussion}

\subsection{Optimal conditions of L. Barbarum crude polysaccharides UAE}

Effect of extraction time on L. Barbarum crude polysaccharides yield

Figure 2 shows the effect of extraction time on percentage yield of crude polysaccharide. The percentage yield increased as the extraction time increased from 20 to $30 \mathrm{~min}$ and then decreased as the extraction time increased to $60 \mathrm{~min}$. This shows that the highest percentage yield of crude polysaccharides (23.55\%) was obtained at extraction time of $30 \mathrm{~min}$. Similar observations were obtained by (Wang et al., 2016; Ying et al., 2011) who respectively, reported that the yield of Artemisia selengensis Turcz polysaccharides and mulberry leaves polysaccharides decreased as the extraction time increased. The Minitab 17 software was used to apply the Tukey's Test to compare to the difference between the means in all treatments. Means that share same letter are (not significantly different).

The greater part of the polysaccharides inside the cells were discharged at the beginning of the extraction, and expanded extraction time would lead to degradation of polysaccharides (Esclapez et al., 2011; Hromádková et al., 1999).

\section{Effect of extraction temperature on L. Barbarum crude polysaccharides yield}

Figure 3 shows the percentage yield of L. Barbarum crude polysaccharides at five temperatures $\left(30,40,50,60\right.$, and $\left.70^{\circ} \mathrm{C}\right)$ at the optimal extraction time of $30 \mathrm{~min}$. The extraction yield started with $17.26 \%$ at temperature of $30{ }^{\circ} \mathrm{C}$, then elevated to $19.46 \%$ and $22.95 \%$ at $50^{\circ} \mathrm{C}$ and $60^{\circ} \mathrm{C}$, respectively. The extracted yield decreased when the temperature exceeded to $70^{\circ} \mathrm{C}$ to give $18.20 \%$. (Zhu et al., 2016) studied the extraction of Polygonum multiflorum polysaccharide, and stated that high temperature could allow the release of polysaccharides from cells to the solvent. These outcomes were likewise because of the impacts of acoustic cavitation and diffusion through the cell walls,

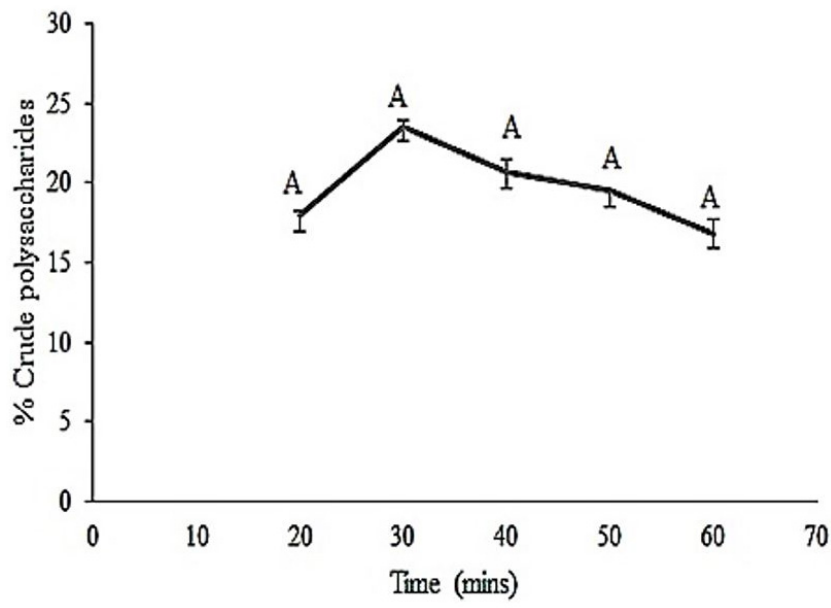

Figure 2. The effect of time on the extracted yield of L. Barbarum crude polysaccharides values are means \pm SD. 
which were improved by the extraction temperature. As the temperature increased, the viscosity coefficient and the surface tension coefficient decreased, which made it less demanding to strengthen the cavitation impact and produce the cavitation bubble (Bai et al., 2017).

However, when the temperature increased further, the vapor pressure increased and this resulted in the decrease of cavitation strength or cavitation effect causing the damping of the ultrasonic wave (Zhao et al., 2007). Resulting, the optimum temperature was $60^{\circ} \mathrm{C}$. Using the Tukey's Test, the results showed (no significant difference).

\section{Effect of solid/liquid ratio on L. Barbarum crude} polysaccharides yield

Figure 4 demonstrates the impact of solid/liquid ratio on the yield of $L$. Barbarum crude polysaccharides. The solid/liquid ratio affected the extraction yield significantly. As the solid/liquid ratio increased from $5 \mathrm{~g} / 600 \mathrm{~mL}$ to $20 \mathrm{~g} / 600 \mathrm{~mL}$, the percentage yield increased from $11.53 \%$ to $26.38 \%$. Under the high temperature condition, the increase of solid/liquid ratio led to increase in liquid viscosity. Because of the expansion in fluid consistency (viscosity), the volume of the cavitation bubbles and the quality of the air bubble fall expanded (Yan et al., 2016), which facilitated the extraction of polysaccharides. Further increase of solid/liquid

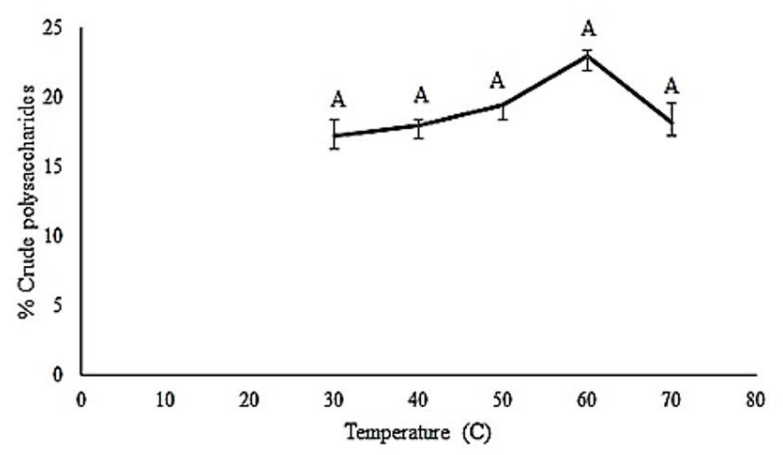

Figure 3. The effect of temperature on the extracted yield of L. Barbarum crude polysaccharides, values are means $\pm \mathrm{SD}$.

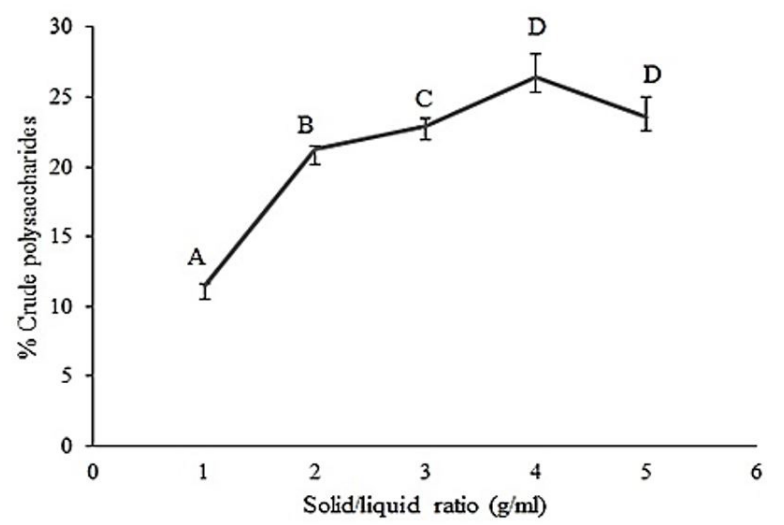

Figure 4. The effect of the solid/liquid ratio on the extracted yield of L. Barbarum crude polysaccharides. Values are means \pm SD. ratio to $25 \mathrm{~g} / 600 \mathrm{~mL}$ led to decrease in the percentage yield. This could be attributed to the fact that when the liquid viscosity was too high, it would cause the decrease of bubble number and the difficulty of collapsing, which decreased the cavitation effect finally. The optimal sample concentration recovered from this test was $20 \mathrm{~g} / 600 \mathrm{~mL}$ as shown in (Figure 4).

The control sample was done by the hot water extraction procedure, using the optimal solid/liquid ratio recovered previously. Since the first, second, third, and forth solid/liquid ratios results don't share letters, thus they are (significantly different). At temperature of $60^{\circ} \mathrm{C}$ for $30 \mathrm{mins}$ and solid/liquid ratio $20 \mathrm{~g} / 600 \mathrm{~mL}$, the crude polysaccharides percentage was $22.45 \%$ (Figure 5 and 6).

\section{Yield of crude polysaccharides using single-frequency UAE mode}

The optimum conditions obtained from the previous part of the study - (extraction time 30 mins, extraction temperature $60^{\circ} \mathrm{C}$ and solid/liquid ratio $20 \mathrm{~g} / 600 \mathrm{~mL}$ ) - were applied to the five frequencies of the single-frequency ultrasound extractor. Figure $5 \mathrm{a}$ shows the percentage yield of crude polysaccharides of the control sample and the five frequencies $(20,28,35,40$, and $50 \mathrm{kHz})$. Results showed that the crude polysaccharides yield increased from $19.53 \%$ at the first frequency $20 \mathrm{kHz}$, to $26.38 \%$ at $28 \mathrm{kHz}$. With the increase of ultrasonic frequency, the cavitation effect of ultrasound increases (Yusof et al., 2016). The mechanical impacts required in ultrasound can permit more penetration of solvent into the sample matrix, the disturbance of the organic cell walls while the ultrasonically actuated cavitation encourages and increments the release of substance (Dolatowski et al., 2007).

However, when the ultrasound frequency elevated to $35 \mathrm{kHz}$ and $40 \mathrm{kHz}$ the extraction yield dropped to $22.71 \%$ and $23.51 \%$, respectively, and finally decreased to $11.88 \%$ at the frequency $50 \mathrm{kHz}$. When the ultrasonic frequency was too high, the time of acoustic expansion became relatively shorter, leading to insufficient time to form the cavitation bubble that generates ultrasonic effect and when the cavitation bubble was formed, the compression phase of acoustic wave was too short, which might be not enough for the cavitation bubble to collapse, thus, a decrease in the cavitation effect occurred (Esclapez et al., 2011; Kentish \& Ashokkumar, 2011). The Tukey's Test showed that the results of $28 \mathrm{kHz}$ and $50 \mathrm{kHz}$ are (significantly different). Therefore, from this result, the optimal frequency for single-frequency UAE mode was $28 \mathrm{kHz}$. (Figure 5a) also showed that the extraction yield at frequency of $28 \mathrm{kHz}$ was $17.5 \%$ greater than the control's.

\section{Yield of crude polysaccharides using dual-frequency UAE mode}

The dual-frequency ultrasound extractor is equipped with four dual-frequencies options, (20/28), (20/35), (20/40) and $(20 / 50) \mathrm{kHz}$. As shown in Figure 5b, the two frequencies options $(20 / 40)$ and $(20 / 28) \mathrm{kHz}$ gave the highest results of $38.93 \%$ and $38.25 \%$, respectively. The higher extract of $L$. Barbarum crude polysaccharides could be clarified by the expanded cavitation bubble crash which brought on additional diminishment in particle measure and advanced leaching. Chukwumah et al, correspondingly detailed that the effect of multi-frequency $\mathrm{UAE}$, is more proficient than single frequency UAE during the 
a)

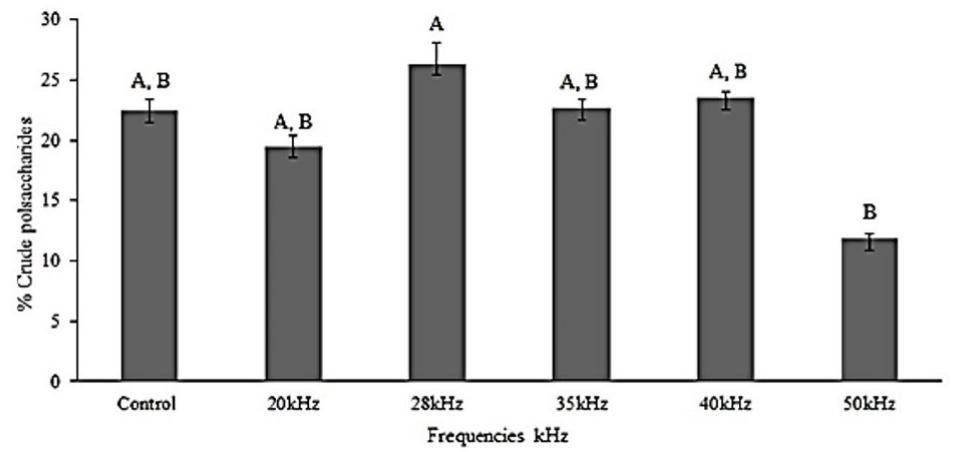

b)
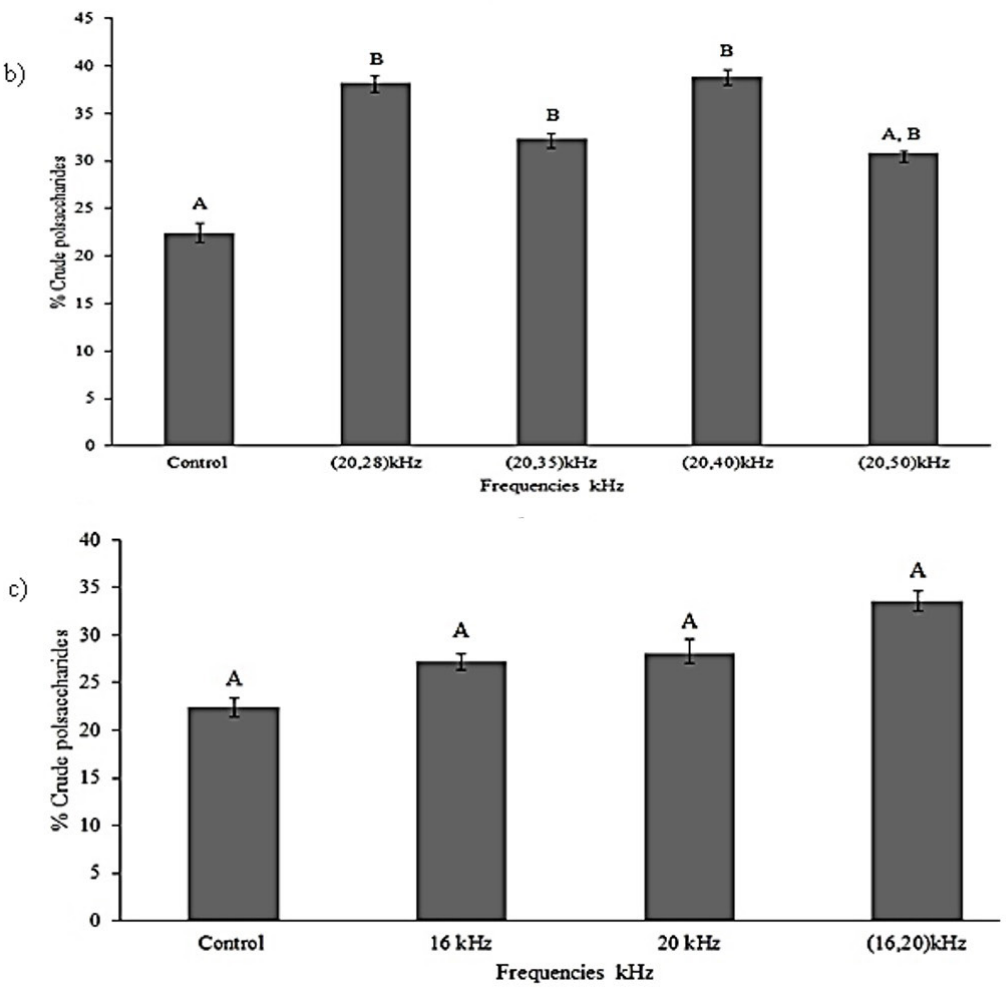

Figure 5. The yields of L. Barbarum crude polysaccharides using: a) single-frequency ultrasound extractor, b) dual-frequency ultrasound extractor, and c) opposite-sit dual-frequency ultrasound extractor. Values are means \pm SD.

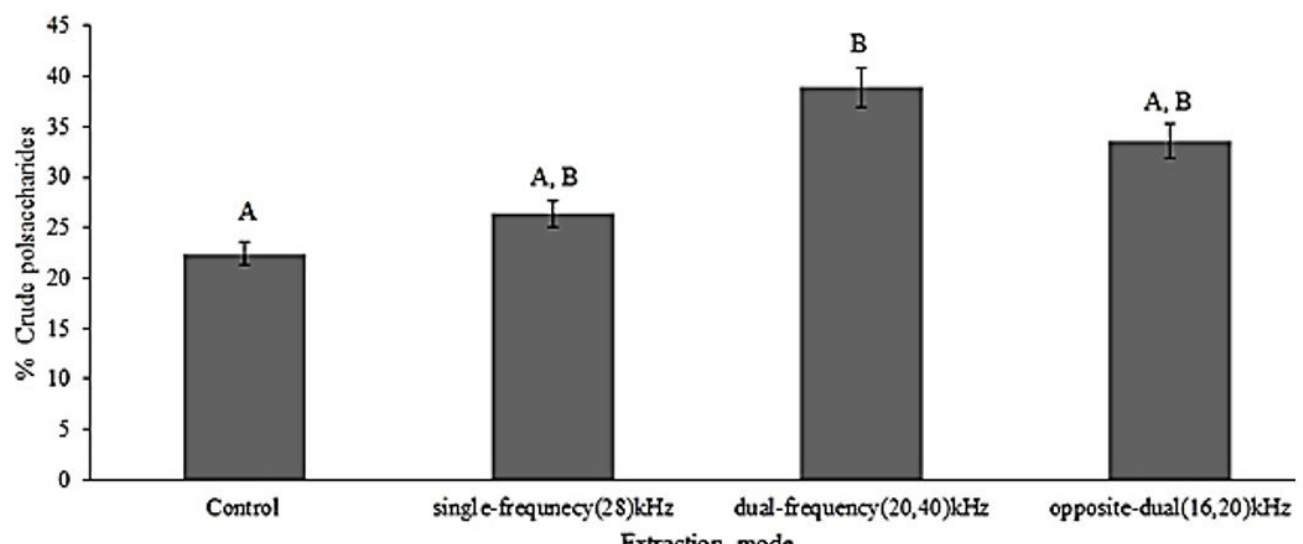

Figure 6. Comparison between control sample and the highest crude polysaccharides extraction yields achieved by each one of the three ultrasound extractors. Values are means \pm SD. 
Table 1. The yield of crude polysaccharides by control and three UAE modes.

\begin{tabular}{ccccc}
\hline Sample & control & single-frequency $(28) \mathrm{kHz}$ & dual-frequency $(20,40) \mathrm{kHz}$ & opposite-dual $(16,20) \mathrm{kHz}$ \\
\hline crude polysaccharides $\%$ & 22.45 & 26.38 & 38.93 & 33.60 \\
\hline
\end{tabular}

extraction of iso-flavones and trans-resveratrol from peanuts (Chukwumah et al., 2009). The results showed (significant difference) between the control and the results of the dual-frequencies except the last dual-frequency $(20 / 50) \mathrm{kHz}$ which is (not significantly different) from the control and the rest of the dual frequencies. The extraction yield at dual frequency of $(20 / 40) \mathrm{kHz}$ was $73.4 \%$ higher than the control yield.

\section{Yield of crude polysaccharides using opposite-sit dual- frequency UAE mode}

In Figure 1c, the opposite-sit dual-frequency ultrasound extractor looks completely different from the previous two extractors. The single-frequency options provided by this extractor are $(16 \mathrm{kHz}$, and $20 \mathrm{kHz})$, and a dual-frequency of $(16 / 20) \mathrm{kHz}$.

Figure $5 \mathrm{c}$ shows the percentage yield of crude polysaccharides for control sample, single and dual frequencies. The single-frequency extracted yield at $16 \mathrm{kHz}$ was $27.28 \%$, and increased gradually to $28.03 \%$ at $20 \mathrm{kHz}$ with no (significant difference). As for the dual- frequency application the extraction yield was $33.60 \%$ at $(16 / 20) \mathrm{kHz}$. These results also indicated that the dual-frequency UAE is more effective for L. Barbarum crude polysaccharides extraction. The percentage yield at dual frequency of $(16 / 20)$ $\mathrm{kHz}$ was $49.6 \%$ higher than the control's yield.

Lernetti et al, stated out to that one possible system for this enhanced impact could come about because of the generation of new bubbles by the low-frequency stimulating field (Lernetti et al., 1997). An alternative could emerge from the diminishing quasi-static pressure during the negative pressure amplitude half-wave of the low-frequency field. This decrease the cavitation threshold of the high frequency field and builds up more bubbles driven by that field. This quasi-static pressure contributes to an increase of the collapse rate during the positive pressure amplitude half-wave of the low-frequency field.

\section{Comparing extraction frequencies among the three UAE modes}

The three ultrasound extractors were run under the same parameters, ultrasound power density $300 \mathrm{~W} / \mathrm{L}$, On/Off ultrasound time ( $5 \mathrm{sec} / 2 \mathrm{sec}$ ), using the optimal conditions for L. Barbarum polysaccharide extraction: time $30 \mathrm{mins}$, temperature $60^{\circ} \mathrm{C}$, and solid/liquid ratio $20 \mathrm{~g} / 600 \mathrm{~mL}$. The energy aggregation counter flow dual-frequency ultrasound extractor gave the highest result among the three extractors, 38.93\% crude polysaccharides. The Opposite-sit dual-frequency ultrasound extractor was the second best followed by the energy aggregation counter flow single-frequency ultrasound extractor as shown in (Table 1) and (Figure 6).

The yield of crude polysaccharides increased by $73.41 \%$ using the dual-frequency ultrasound extraction compared by traditional hot water extraction. The Tukey's Test showed (significant difference) between the control and the dual-frequency ultrasound extraction $(20,40) \mathrm{kHz}$. This also caused a reduction in temperature and extraction time to $33.3 \%$ and $50 \%$ respectively.

\section{Conclusion}

The UAE has been considered an effective method for the extraction of bioactive components from plants. The first aim of this study was to find out the optimal condition for Lycium Barbarum crude polysaccharides by UAE. The extraction optimal conditions were as follows: extraction time of 30 mins, extraction temperature of $60^{\circ} \mathrm{C}$, and solid/liquid ratio of $20 \mathrm{~g} / 600 \mathrm{~mL}$. Under these conditions, the Lycium Barbarum crude polysaccharides yield was $26.38 \%$ for single frequency at $28 \mathrm{kHz}$.

The second aim of the study was to apply these extraction conditions on three UAE modes to test different frequencies. The energy aggregation counter flow dual-frequency UAE mode gave the highest yield of $38.93 \%$ at the dual-frequency of $(20,40) \mathrm{kHz}$.

This study clearly showed that the dual frequency mode gave a higher polysaccharides extraction compared to the single-frequency mode and the traditional hot water extraction.

\section{Acknowledgements}

This research work was supported by grant from the Prospective Research Project of Jiangsu Province, China (BY2013065-01).

\section{References}

Amagase, H. (2014). Antioxidants in Goji Berry juice (Lycium barbarum) and effects of processing steps A2. In V. Preedy. Processing and impact on antioxidants in beverages (chap. 16, pp. 155-163). San Diego: Academic Press.

Amagase, H., \& Farnsworth, N. R. (2011). A review of botanical characteristics, phytochemistry, clinical relevance in efficacy and safety of Lycium barbarum fruit (Goji). Food Research International, 44(7), 1702-1717. http://dx.doi.org/10.1016/j.foodres.2011.03.027.

Ashokkumar, M. (2015). Applications of ultrasound in food and bioprocessing. Ultrasonics Sonochemistry, 25, 17-23. PMid:25219872. http://dx.doi. org/10.1016/j.ultsonch.2014.08.012.

Azmir, J., Zaidul, I. S. M., Rahman, M. M., Sharif, K. M., Mohamed, A., Sahena, F., Jahurul, M. H. A., Ghafoor, K., Norulaini, N. A. N., \& Omar, A. K. M. (2013). Techniques for extraction of bioactive compounds from plant materials: a review. Journal of Food Engineering, 117(4), 426-436. http://dx.doi.org/10.1016/j.jfoodeng.2013.01.014.

Bai, L., Chen, X., Zhu, G., Xu, W., Lin, W., Wu, P., Li, C., Xu, D., \& Yan, J. (2017). Surface tension and quasi-emulsion of cavitation bubble cloud. Ultrasonics Sonochemistry, 35(Part A), 405-414. http://dx.doi. org/10.1016/j.ultsonch.2016.10.019.

Bo, R., Zheng, S., Xing, J., Luo, L., Niu, Y., Huang, Y., Liu, Z., Hu, Y., Liu, J., Wu, Y., \& Wang, D. (2016). The immunological activity of Lycium barbarum polysaccharides liposome in vitro and adjuvanticity against PCV2 in vivo. International Journal of Biological Macromolecules, 85, 294301. PMid:26763175. http://dx.doi.org/10.1016/j.ijbiomac.2015.12.089. 
Chemat, F., Zill-e-Huma, \& Khan, M. K. (2011). Applications of ultrasound in food technology: processing, preservation and extraction. Ultrasonics Sonochemistry, 18(4), 813-835. PMid:21216174. http://dx.doi.org/10.1016/j. ultsonch.2010.11.023.

Cheung, Y.-C., Siu, K.-C., \& Wu, J.-Y. (2013). Kinetic models for ultrasoundassisted extraction of water-soluble components and Polysaccharides from medicinal Fungi. Food and Bioprocess Technology, 6(10), 26592665. http://dx.doi.org/10.1007/s11947-012-0929-z.

Chukwumah, Y. C., Walker, L. T., Verghese, M., \& Ogutu, S. (2009). Effect of frequency and duration of ultrasonication on the extraction efficiency of selected isoflavones and trans-resveratrol from peanuts (Arachis hypogaea). Ultrasonics Sonochemistry, 16(2), 293-299. PMid:18849184. http://dx.doi.org/10.1016/j.ultsonch.2008.07.007.

Cravotto, G., \& Binello, A. (2016). Low-frequency, high-power ultrasoundassisted food component extraction. In K. Knoerze, P. Juliano \& G. Smithers (Eds.), Innovative food processing technologies (chap. 1, pp. 3-29). Sawston: Woodhead Publishing.

Cui, B., Chen, Y., Liu, S., Wang, J., Li, S., Wang, Q., Li, S., Chen, M., \& Lin, X. (2012). Antitumour activity of Lycium chinensis polysaccharides in liver cancer rats. International Journal of Biological Macromolecules, 51(3), 314318. PMid:22579736. http://dx.doi.org/10.1016/j.ijbiomac.2012.05.004.

Dolatowski, Z. J., Stadnik, J., \& Stasiak, D. (2007). Applications of ultrasound in food technology. Acta Scientiarum Polonorum. Technologia Alimentaria, 6(3), 88-99.

DuBois, M., Gilles, K. A., Hamilton, J. K., Rebers, P. A., \& Smith, F. (1956). Colorimetric method for determination of Sugars and Related Substances. Analytical Chemistry, 28(3), 350-356. http://dx.doi.org/10.1021/ ac60111a017.

Esclapez, M. D., García-Pérez, J. V., Mulet, A., \& Cárcel, J. A. (2011). Ultrasound-assisted extraction of natural products. Food Engineering Reviews, 3(2), 108-120. http://dx.doi.org/10.1007/s12393-011-9036-6.

Fernandes, F. A. N., Rodrigues, S., Cárcel, J. A., \& García-Pérez, J. V. (2015). Ultrasound-Assisted Air-Drying of Apple (Malus domestica L.) and Its Effects on the Vitamin of the Dried Product. Food and Bioprocess Technology, 8(7), 1503-1511. http://dx.doi.org/10.1007/s11947-015-1519-7.

Hromádková, Z., Ebringerová, A., \& Valachovič, P. (1999). Comparison of classical and ultrasound-assisted extraction of polysaccharides from Salvia officinalis L. Ultrasonics Sonochemistry, 5(4), 163-168. PMid:11269956. http://dx.doi.org/10.1016/S1350-4177(98)00046-7.

Jin, J., Ma, H., Wang, K., Yagoub, A. E.-G. A., Owusu, J., Qu, W., He, R., Zhou, C., \& Ye, X. (2015). Effects of multi-frequency power ultrasound on the enzymolysis and structural characteristics of corn gluten meal. Ultrasonics Sonochemistry, 24, 55-64. PMid:25577971. http://dx.doi. org/10.1016/j.ultsonch.2014.12.013.

Kadam, S. U., Tiwari, B. K., Álvarez, C., \& O’Donnell, C. P. (2015). Ultrasound applications for the extraction, identification and delivery of food proteins and bioactive peptides. Trends in Food Science \& Technology, 46(1), 60-67. http://dx.doi.org/10.1016/j.tifs.2015.07.012.

Kentish, S., \& Ashokkumar, M. (2011). The physical and chemical effects of ultrasound. In H. Feng, G. Barbosa-Canovas \& J. Weiss (Eds.), Ultrasound technologies for food and bioprocessing (pp. 1-12). New York: Springer New York.

Lernetti, G., Ciuti, P., Dezhkunov, N. V., Reali, M., Francescutto, A., \& Johri, G. K. (1997). Enhancement of high-frequency acoustic cavitation effects by a low-frequency stimulation. Ultrasonics Sonochemistry, 4(3), 263-268. PMid:11232783. http://dx.doi.org/10.1016/S1350-4177(97)00034-5.

Li, X. M. (2007). Protective effect of Lycium barbarum polysaccharides on streptozotocin-induced oxidative stress in rats. International Journal of Biological Macromolecules, 40(5), 461-465. PMid:17166579. http:// dx.doi.org/10.1016/j.ijbiomac.2006.11.002.

Peralta-Jiménez, L., \& Cañizares-Macías, M. P. (2013). Ultrasound-Assisted method for extraction of Theobromine and Caffeine from Cacao seeds and chocolate products. Food and Bioprocess Technology, 6(12), 35223529. http://dx.doi.org/10.1007/s11947-012-1014-3.
Potterat, O. (2010). Goji (Lycium barbarum and L. chinense): phytochemistry, pharmacology and safety in the perspective of traditional uses and recent popularity. Planta Medica, 76(1), 7-19. PMid:19844860. http:// dx.doi.org/10.1055/s-0029-1186218.

Raza, A., Li, F., Xu, X., \& Tang, J. (2017). Optimization of ultrasonicassisted extraction of antioxidant polysaccharides from the stem of Trapa quadrispinosa using response surface methodology. International Journal of Biological Macromolecules, 94(Part A), 335-344. http://dx.doi. org/10.1016/j.ijbiomac.2016.10.033.

Vilkhu, K., Mawson, R., Simons, L., \& Bates, D. (2008). Applications and opportunities for ultrasound assisted extraction in the food industry: a review. Innovative Food Science \& Emerging Technologies, 9(2), 161-169. http://dx.doi.org/10.1016/j.ifset.2007.04.014.

Wang, C. C., Chang, S. C., \& Chen, B. H. (2009). Chromatographic determination of polysaccharides in Lycium barbarum Linnaeus. Food Chemistry, 116(2), 595-603. http://dx.doi.org/10.1016/j.foodchem.2009.03.015.

Wang, J., Lu, H. D., Muḥammad, U., Han, J. Z., Wei, Z. H., Lu, Z. X., Bie, X. M., \& Lu, F. X. (2016). Ultrasound-assisted extraction of polysaccharides from Artemisia selengensis Turcz and its antioxidant and anticancer activities. Journal of Food Science and Technology, 53(2), 1025-1034. PMid:27162382. http://dx.doi.org/10.1007/s13197-015-2156-x.

Wu, Y., Cui, S. W., Tang, J., \& Gu, X. (2007). Optimization of extraction process of crude polysaccharides from boat-fruited sterculia seeds by response surface methodology. Food Chemistry, 105(4), 1599-1605. http://dx.doi.org/10.1016/j.foodchem.2007.03.066.

Xie, J.-H., Tang, W., Jin, M.-L., Li, J.-E., \& Xie, M.-Y. (2016). Recent advances in bioactive polysaccharides from Lycium barbarum L., Zizyphus jujuba Mill, Plantago spp., and Morus spp.: structures and functionalities. Food Hydrocolloids, 60, 148-160. http://dx.doi.org/10.1016/j.foodhyd.2016.03.030.

Xin, T., Yao, H., Gao, H., Zhou, X., Ma, X., Xu, C., Chen, J., Han, J., Pang, X., Xu, R., Song, J., \& Chen, S. (2013). Super food Lycium barbarum (Solanaceae) traceability via an internal transcribed spacer 2 barcode. Food Research International, 54(2), 1699-1704. http://dx.doi.org/10.1016/j. foodres.2013.10.007.

Yan, J.-K., Wang, Y.-Y., Ma, H.-L., \& Wang, Z.-B. (2016). Ultrasonic effects on the degradation kinetics, preliminary characterization and antioxidant activities of polysaccharides from Phellinus linteus mycelia. Ultrasonics Sonochemistry, 29, 251-257. PMid:26585005. http://dx.doi. org/10.1016/j.ultsonch.2015.10.005.

Yang, X., Li, Y., Li, S., Oladejo, A. O., Wang, Y., Huang, S., et al (2017). Effects of low power density muti-frequency ultrasound pretreatment on the enzymolysis and the structure characterization of defatted wheat germ protein. Ultrasonics Sonochemistry. http://dx.doi.org/10.1016/j. ultsonch.2017.03.001.

Ying, Z., Han, X., \& Li, J. (2011). Ultrasound-assisted extraction of polysaccharides from mulberry leaves. Food Chemistry, 127(3), 12731279. PMid:25214126. http://dx.doi.org/10.1016/j.foodchem.2011.01.083.

Yusof, N. S. M., Babgi, B., Alghamdi, Y., Aksu, M., Madhavan, J., \& Ashokkumar, M. (2016). Physical and chemical effects of acoustic cavitation in selected ultrasonic cleaning applications. Ultrasonics Sonochemistry, 29, 568-576. PMid:26142078. http://dx.doi.org/10.1016/j. ultsonch.2015.06.013.

Zhao, S., Kwok, K.-C., \& Liang, H. (2007). Investigation on ultrasound assisted extraction of saikosaponins from Radix Bupleuri. Separation and Purification Technology, 55(3), 307-312. http://dx.doi.org/10.1016/j. seppur.2006.12.002.

Zhu, W., Xue, X., \& Zhang, Z. (2016). Ultrasonic-assisted extraction, structure and antitumor activity of polysaccharide from Polygonum multiflorum. International Journal of Biological Macromolecules, 91, 132142. PMid:27212220. http://dx.doi.org/10.1016/j.ijbiomac.2016.05.061. 